\title{
The Second Conference of CIS Countries "Sol-Gel-2012", Sevastopol, Crimea, Ukraine, September 18-20, 2012
}

\author{
Yuriy L. Zub
}

Published online: 13 November 2013

(C) Springer Science+Business Media New York 2013

The Second Conference of CIS Countries "Sol-Gel-2012" was held in Sevastopol, Ukraine and organized by the Institute for Sorption and Problems of Endoecology and the Chuiko Institute of Surface Chemistry of NAS of Ukraine (Kyiv) with the support of the Grebenshchikov Institute of Silicate Chemistry of RAS (St.-Petersburg, Russia). 135 scientists and experts from different scientific centers of the Russian Federation, Ukraine, Republic of Belarus, Armenia and Kazakhstan have participated to the conference. About half of these participants were young scientists and graduate students and have greatly contributed to the success of the meeting. In addition, 15 researchers from other countries (Austria, Hungary, Lithuania, Canada, Slovenia, Poland, Sweden, Czech Republic, and Finland) also took part to the Conference.

"Sol-Gel-2012" covered the following sections: theoretical aspects of sol-gel process, sol-gel synthesis and study of nanoparticles, sol-gel films, coatings and membranes, hybrid inorganic and organic-inorganic sol-gel materials, xerogels, glass and bulk ceramic materials, sorbents, and catalysts synthesized by the sol-gel method and biomedical materials. 17 plenary lectures and 30 short oral presentations have been presented during the conference. Moreover 110 posters have been discussed during two poster sessions. The opening speech was delivered by the
Co-Chair of the Conference, Academician of NASU V.V. Strelko. In the beginning, he read an address to the participants of "Sol-Gel-2012", written by the President of NAS of Ukraine, Acad. Boris Paton; then he briefly outlined the historical aspects of the chemistry and technology of sol-gel processes.

One of the objectives of the Conference, the strengthening in the mutually beneficial research cooperation between researchers originated from the CIS countries and other foreign countries has been fully achieved. Undoubtedly, this Conference gave new impetus in the CIS countries to the research in chemistry and technology of sol-gel processes.

The organizers have selected the most interesting presentations made during this Conference which will certainly be of great interest for sol-gel readers; they can be found in this special issue of the "Journal of Sol-Gel Science and Technology" (Fig. 1).

The future meetings of the CIS Countries have been already decided: the Third Conference "Sol-Gel-2014" will be held in Suzdal, Russia and organized by the Krestov Institute of Solution Chemistry of RAS, Ivanovo, Russia, while the Fourth Conference "Sol-Gel-2016" will take place in Yerevan (Armenia) and organized by the Yerevan State University, Armenia.

Y. L. Zub (ه)

Kyiv, Ukraine

e-mail: zub_yuriy@isc.gov.ua 


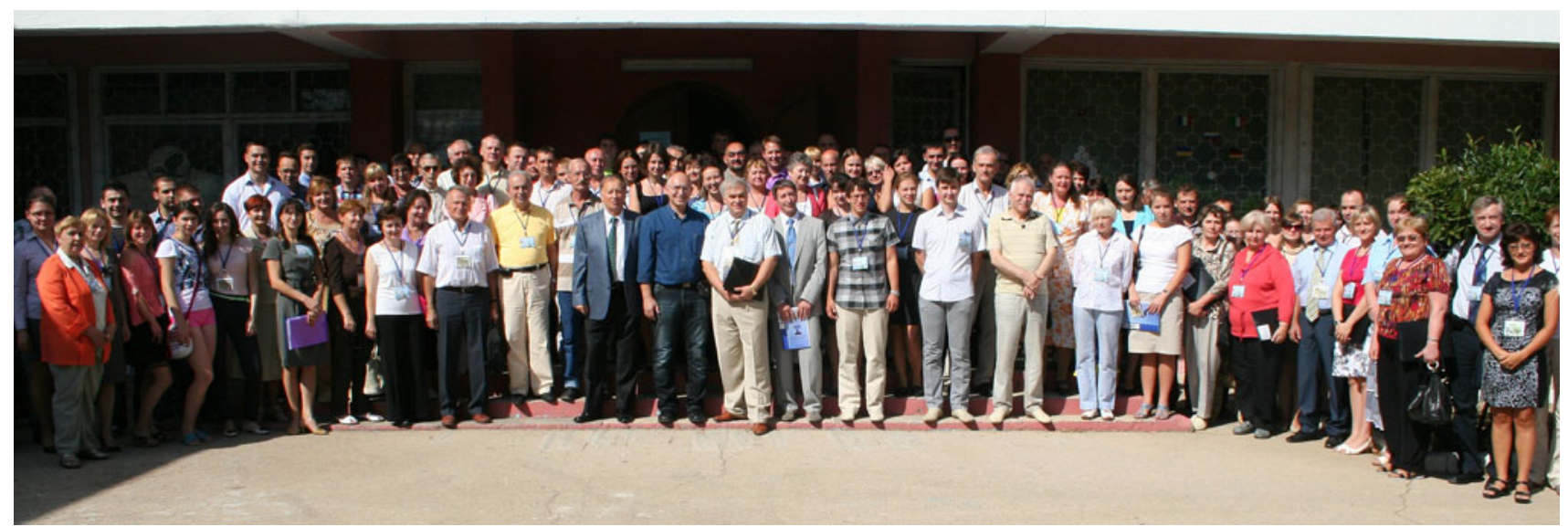

Fig. 1 Picture of the participants of the conference "CIS countries Sol-Gel 2012". In the center: Acad. of NAS of Ukraine, Prof. V. V. Strelko, Prof. Dr. V. G. Kessler and Prof. Dr. Yu. L. Zub (holding a briefcase) 